\title{
Complications Following Surgery for Gastric Cancer: Analysis of Prospectively Collected Data
}

\author{
Lorenzo Bruno ${ }^{1 *}$, Lucia Barni' ${ }^{1}$, Sabrina Pacciani ${ }^{1}$, Gaia Masini', Lorenzo Tofani², \\ Federica Tofani' ${ }^{1}$, Filippo Melli', Antonio Taddei', Manuela Andonova Miloeva', \\ Luca Boni' ${ }^{2}$, Giancarlo Freschi' ${ }^{1}$, Paolo Bechi ${ }^{1}$ \\ ${ }^{1}$ Department of Surgery and Translational Medicine, University of Florence, Florence, Italy \\ ${ }^{2}$ Clinical Trials Coordinating Center, Azienda Ospedaliero-Universitaria Careggi, Florence, Italy \\ Email: "Ibruno@katamail.com
}

Received 17 October 2014; revised 18 November 2014; accepted 27 November 2014

Academic Editor: Sibu P. Saha, University of Kentucky, USA

Copyright (C) 2014 by authors and Scientific Research Publishing Inc.

This work is licensed under the Creative Commons Attribution International License (CC BY). http://creativecommons.org/licenses/by/4.0/

(c) (7) Open Access

\section{Abstract}

Background and Aims: The complication rate after surgery for gastric cancer varies according to the particular definition of morbidity, so it's necessary to report them using a standardized method, the Clavien-Dindo system. The purpose of this study was to prospectively analyze all postgastrectomy complications in patients with gastric adenocarcinoma according to the severity grade using Clavien-Dindo system, in order to identify risk factors for postoperative complications and their prognostic significance on survival. Methods: This study is based on data from 90 consecutive patients who underwent gastrectomy for gastric neoplasia between January 2010 and February 2014 at the same unit. 15 patients were excluded (benign tumors, GISTs, missing data). Complications were categorized according to the Clavien-Dindo classification (uncomplicated patients vs patients classified $\geq$ Grade I). The following risk factors were studied: age, BMI, sex, operation method, extent of resection, duration of surgery, transfusions, TNM staging, and lymph node ratio. Multivariate logistic regression was used to evaluate the association between risk factors and presence of complications. To assess the effect on overall survival, after selection of covariates using backward elimination, the Cox proportional hazard model was applied. Results: Among these patients, 49 (65.3\%) developed complications, stratified as follows: Grade I, 6 (8\%); Grade II, 24 (32\%); Grade III, 6 (8\%); Grade IV, 13 (17.3\%). The laparoscopic technique (OR = 0.050; 95\% CI = 0.005 - 0.550, p $=0.0143)$ and no transfusions $(\mathrm{OR}=0.219 ; 95 \% \mathrm{CI}=0.058-0.827, \mathrm{p}=\mathbf{0 . 0 2 5 1})$ were found to reduce the incidence of postoperative complications in the multivariate analysis. With regard to the survival analysis, lymph node ratio, malnutrition, extended resection and presence of complications were significant predictors of reduced survival in the multivariate analysis. Conclusions:

\footnotetext{
${ }^{*}$ Corresponding author.
}

How to cite this paper: Bruno, L., Barni, L., Pacciani, S., Masini, G., Tofani, L., Tofani, F., Melli, F., Taddei, A., Miloeva, M.A., Boni, L., Freschi, G. and Bechi, P. (2014) Complications Following Surgery for Gastric Cancer: Analysis of Prospectively Collected Data. Journal of Cancer Therapy, 5, 1454-1466. http://dx.doi.org/10.4236/jct.2014.514147 
Some variables can predict the risk of postoperative complications, the occurrence of which is a predictor of reduced probability of survival. In this respect it's essential to reduce complications.

\author{
Keywords
}

\author{
Gastric Cancer, Complications, Clavien-Dindo Classification, Survival Probability
}

\title{
1. Introduction
}

Gastric cancer is the fourth most common malignancy and the second most common cause of cancer-related death worldwide [1]. Italy is classified as an intermediate incidence area for gastric cancer.

Surgery still remains the main method for successful treatment of gastric cancer and the incidence of postoperative complications can be regarded as an index showing the outcomes of surgical performance [2].

Accurate grading of complications is essential to analyze surgical outcomes, but methods for classification of complications are not uniform. The Clavien-Dindo system, proposed in 2004 [3], has been applied to many surgeries [4]-[8] and has been considered simple, reproducible, flexible, and irrespective of the cultural background. Moreover an increasing number of studies using this classification for assessing gastric cancer surgery have been published [1] [2] [4] [5].

Many studies have shown that, in gastric cancer, the presence/absence of complications is an important factor that could influence the prognosis of patients following curative gastrectomy [1] [5].

In gastric surgery the most commonly reported complications were intra-abdominal abscesses, wound infection, necrosis or dehiscence, diffuse peritonitis, sepsis, malnutrition, fluid and electrolyte disturbances, acute cholecystitis, pancreatitis, abdominal bleeding and pneumonia [9]. Less common ones are represented by: anastomotic leakage, fistula of duodenal stump, pancreatic fistula and chylous fistula [10].

The reason why post-operative complications affect prognosis remains open to speculation; many studies [1] [5] suggest that prolonged inflammatory response could promote metastatic diffusion of residual tumor cells.

The aims of this study were: firstly, to analyze post-gastrectomy complications for gastric adenocarcinoma by prospectively collecting complication data according to the Clavien-Dindo system in order to investigate risk factors for post-operative complications; secondly, to assess the impact of postoperative complications on longterm survival.

\section{Materials and Methods}

The present study was limited to the last years of our series because it seemed mandatory to evaluate data prospectively collected on account of the peculiar accuracy of Clavien-Dindo classification.

\subsection{Patients}

A total of 90 consecutive patients with gastric neoplasia underwent surgery between January 2010 and February 2014 in our surgical unit, that is a secondary-care unit located in a high-risk gastric cancer area. Eligibility criteria for inclusion in this study were as follows: 1 ) gastric adenocarcinoma identified by histopathological examination; 2) availability of information regarding postoperative complications and mortality. As a result, 75 patients were eligible, whereas 15 patients were excluded: 2 GISTs, 1 lymphoma, 6 benign tumors, 6 missing data. Patients were asked about their informed consent and approval by the ethic committee was requested. For each patient we analyzed the following parameters: age, sex, BMI, operation method, extent of resection, duration of surgery, pre- and intra-operative transfusions, TNM staging, lymph node ratio. 5 patients were lost to follow-up, so they were excluded from the survival analysis. 70 patients were followed up for a minimum of 6 months after gastric resection.

\subsection{Assessment of Complications}

The Clavien-Dindo classification was used to grade post-operative complications: complications were defined as "any deviation from an uneventful post-operative course" within the hospital stay and we considered as complicated patients those with complication grade $\geq$ I (Table 1). 
Table 1. Classification of complication according Clavien-Dindo system.

\begin{tabular}{|c|c|}
\hline Grades & Definition \\
\hline \multirow{2}{*}{ Grade I } & $\begin{array}{l}\text { Any deviation from the normal postoperative course without the need for pharmacological treatment or surgical, } \\
\text { endoscopic and radiological interventions. }\end{array}$ \\
\hline & $\begin{array}{l}\text { Allowed therapeutic regimens are: drugs as antiemetics, antipyretics, analgetics, diuretics and electrolytes and } \\
\text { physiotherapy. This grade also includes wound infections opened at the bedside. }\end{array}$ \\
\hline \multirow{2}{*}{ Grade II } & Requiring pharmacological treatment with drugs other than such allowed for Grade I complications. \\
\hline & Blood transfusions and total parenteral nutrition are also included. \\
\hline Grade III & Requiring surgical, endoscopic or radiological intervention. \\
\hline IIIa & Intervention not under general anesthesia. \\
\hline IIIb & Intervention under general anesthesia. \\
\hline Grade IV & Life-threatening complication (including CNS complications) ${ }^{\ddagger}$ requiring IC/ICU-management. \\
\hline Iva & Single organ dysfunction (including dialysis). \\
\hline $\mathbf{I V b}$ & Multi organ dysfunction. \\
\hline Grade V & Death of a patient. \\
\hline Suffix “d” & $\begin{array}{l}\text { If the patient suffers from a complication at the time of discharge, the suffix "d" (for "disability") is added to the } \\
\text { respective grade of complication. This label indicates the need for a follow-up to fully evaluate the complication. }\end{array}$ \\
\hline
\end{tabular}

${ }^{\ddagger}$ Brain hemorrhage, ischemic stroke, subarrachnoidal bleeding, but excluding transient ischemic attacks (TIA); IC: Intermediate care; ICU: Intensive care unit.

\subsection{Statistical Analysis}

All statistical analyses were performed by SAS Version 9.3. Spearman's rank correlation coefficient was used to identify relation between quantitative parameters and chi-square index for qualitative variables. To evaluate the association between qualitative and quantitative parameters the simple linear regression was applied.

Multivariate logistic regression was used to evaluate the association between risk factors and presence of complications. Stepwise approach for variable selection was used. To evaluate discriminant capability of the risk factors included in the model, area under ROC curve was used.

To evaluate the association between qualitative and quantitative variables and complications chi-square test was used. Survival analysis was performed by Kaplan-Meier curves with log-rank test. To assess the effect on overall survival, after selection of covariates using backward elimination, the Cox proportional hazard model was applied. $\mathrm{p}<0.05$ indicated significant differences.

\section{Results}

\subsection{Patient Characteristics}

Clinicopathological characteristics of the 75 patients are summarized in Table 2. As far as the operative technique is concerned, open, laparoscopic and laparoscopic converted to open gastrectomies were performed respectively in 48 (64\%), 11 (14.7\%) and 16 (21.3\%) cases. Lymph node ratio (NR) was stratified into 3 groups: $0,>0$ and $<0.2, \geq 0.2$. Duration of surgery was significantly shorter in the open surgery group (Table 3 ). The mean duration of hospitalization was $12 \pm 4.8$ days and the median was 10 (ranging between 7 and 32) (Table 4).

\subsection{Postoperative Complications}

Of the 75 patients who underwent gastrectomy, 49 (65.3\%) developed complications. The numbers of ClavienDindo Grade I, II, III, IV and V complications were 6 (8\%), 24 (32\%), 6 (8\%), 13 (17.3\%) and 0 (0\%), respectively (Figure 1).

\subsection{Structured Data Analysis}

After assessing the absence of correlation between the above-mentioned parameters, using a multivariate logistic 
Table 2. Clinical records 2010-2014: 75 patients.

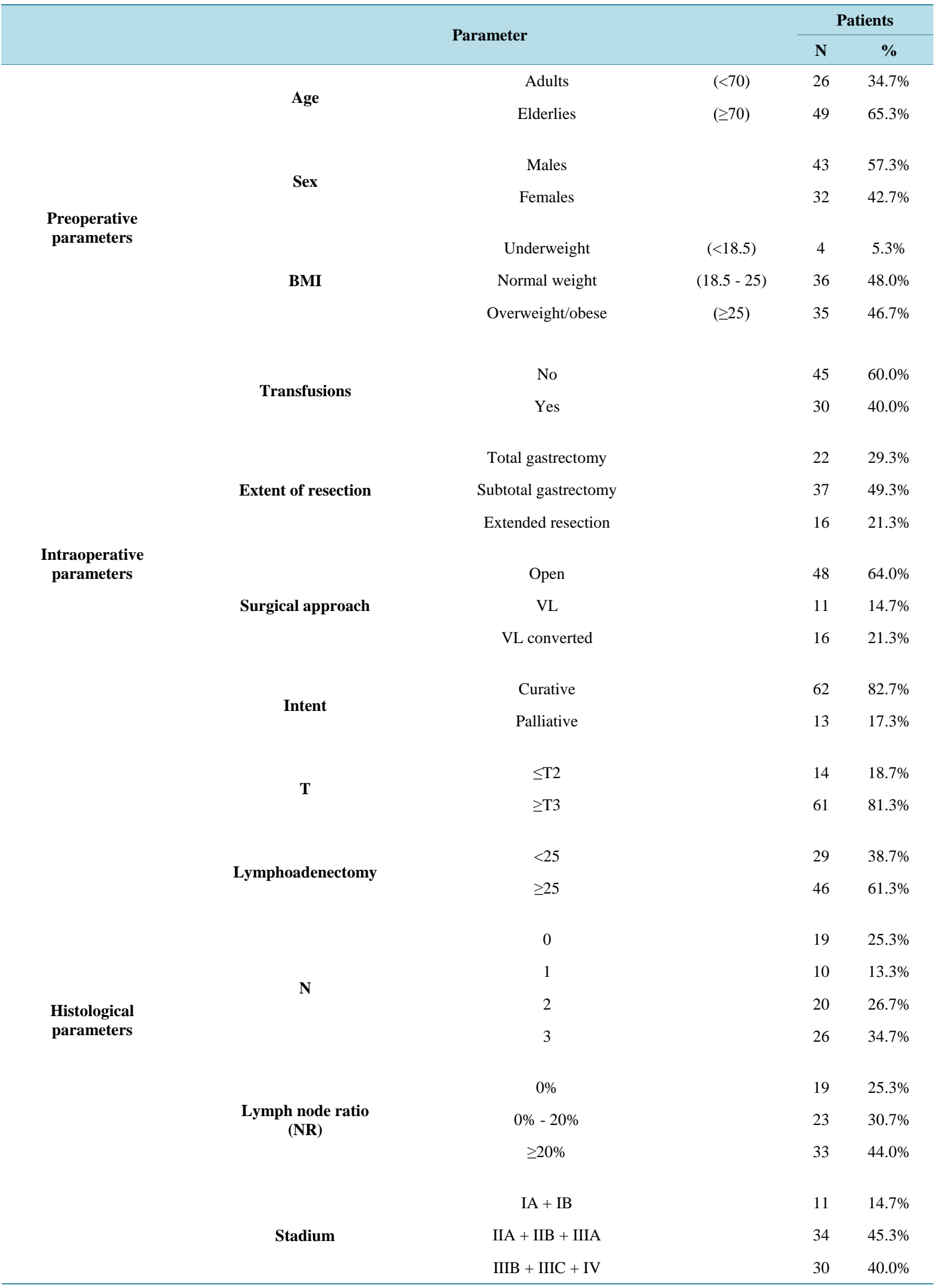


Table 3. Duration of operation (minutes).

\begin{tabular}{cccccc}
\hline Operation approach & Mean & Dev. std. & Median & Minimum & Maximum \\
\hline Open & 227.81 & 62.21 & 217.50 & 150.00 & 425.00 \\
VL & 329.09 & 45.65 & 345.00 & 240.00 & 390.00 \\
VL converted & 280.62 & 69.08 & 280.00 & 160.00 & 450.00 \\
\hline
\end{tabular}

Table 4. Duration of hospitalization (days).

\begin{tabular}{cccccc}
\hline Operation approach & Mean & Dev. std. & Median & Minimum & Maximum \\
\hline Open & 12.56 & 5.32 & 10.00 & 8.00 & 32.00 \\
VL & 9.90 & 3.20 & 9.00 & 7.00 & 19.00 \\
VL converted & 11.68 & 3.60 & 10.00 & 8.00 & 19.00 \\
\hline
\end{tabular}

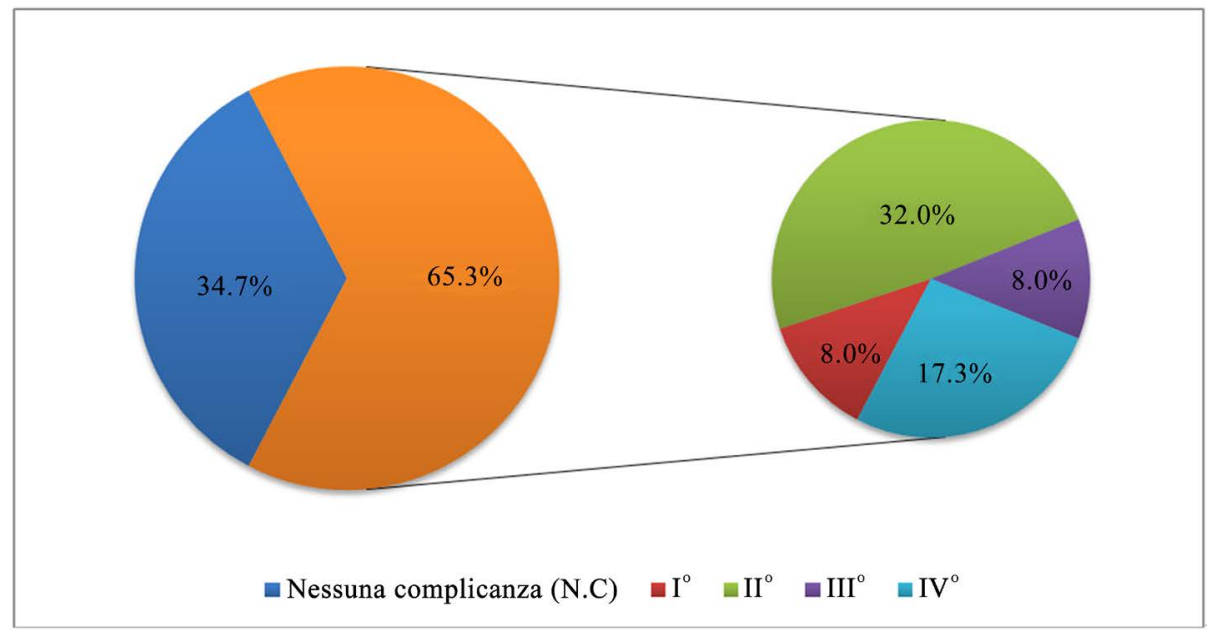

Figure 1. Incidence of complications.

regression model, significant factors were: the laparoscopic technique $(\mathrm{OR}=0.050 ; 95 \% \mathrm{CI}=0.005-0.550, \mathrm{p}=$ 0.0143 ) and no transfusions ( $\mathrm{OR}=0.219 ; 95 \% \mathrm{CI}=0.058-0.827, \mathrm{p}=0.0251)$, which were found to reduce post-operative complications (Table 5). The area under the ROC curve (Figure 2) for these factors is 76\%: it shows that the significant factors which were found can quite well identify post-operative complicated patients. In Figure 3 we can see the expected probability to develop a post-operative complication based on identified factors: when a patient undergoing open technique and received pre-operative or intra-operative transfusions, the probability to have a post-operative complication is $90 \%$, conversely, in patients undergoing laparoscopy and without transfusions, the probability falls to $1 \%$.

Afterwards, the influence of post-operative complications and other risk factors on survival was evaluated. As far as perioperative transfusions are concerned, the differences between survival curves do not attain statistical significance $(p=0.3775)$ (Figure 4). On univariate analysis (Figure 5$)$, complications are significant factors for survival: the probability of 1 year survival after the operation in a complicated patient is about $75 \%$, whereas in a non complicated patient is $95 \%$. Dividing complications in 3 levels (not complicated, complicated I-II, complicated $\geq$ III which are life-threatening complications), this significance is evident (Figure 6). BMI $(\mathrm{p}=0.0252)$ and NR $(p=0.0033)$ are also important. Then, using the Cox proportional hazards regression model, independent prognostic factors were (Table 6).

- Post-operative complications: patients complicated $\geq$ Grade I have a poorer prognosis than not complicated $(\mathrm{HR}=7.39 ; 95 \% \mathrm{CI}=1.64-33.21, \mathrm{p}=0.0091)$;

- BMI: underweight patients have a worse prognosis than overweight/obese $(\mathrm{HR}=8.402$; $95 \% \mathrm{CI}=1.08$ 64.90, $\mathrm{p}=0.0413$ ); 
Table 5. Multivariate analysis: risk factors for complications (LOGIT model).

\begin{tabular}{|ccccccccc}
\hline \multicolumn{7}{|c}{ Analysis of maximum likelihood estimates } \\
\hline \multicolumn{2}{|c}{ Parameter } & Estimate & Standard error & Wald $\chi^{2}$ & p & Odds ratio & 95\% CI \\
\hline \multirow{2}{*}{ Transfusions } & NO & -1.5172 & 0.6772 & 5.0201 & 0.0251 & 0.219 & $0.058-0.827$ \\
$\begin{array}{c}\text { Surgical } \\
\text { approach }\end{array}$ & VL & -2.9941 & 1.2224 & 5.9996 & 0.0143 & 0.05 & $0.005-0.550$ \\
& VL converted & -0.9878 & 0.7337 & 1.8126 & 0.1782 & 0.372 & $0.088-1.569$
\end{tabular}

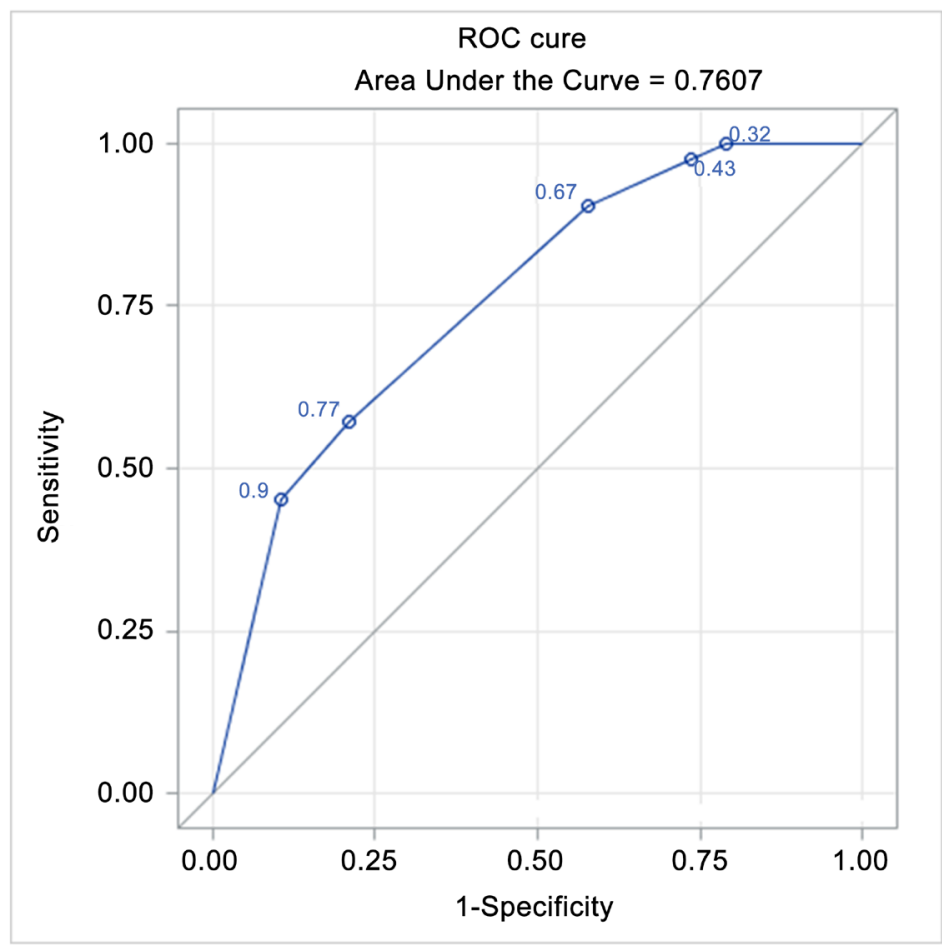

Figure 2. ROC curve.

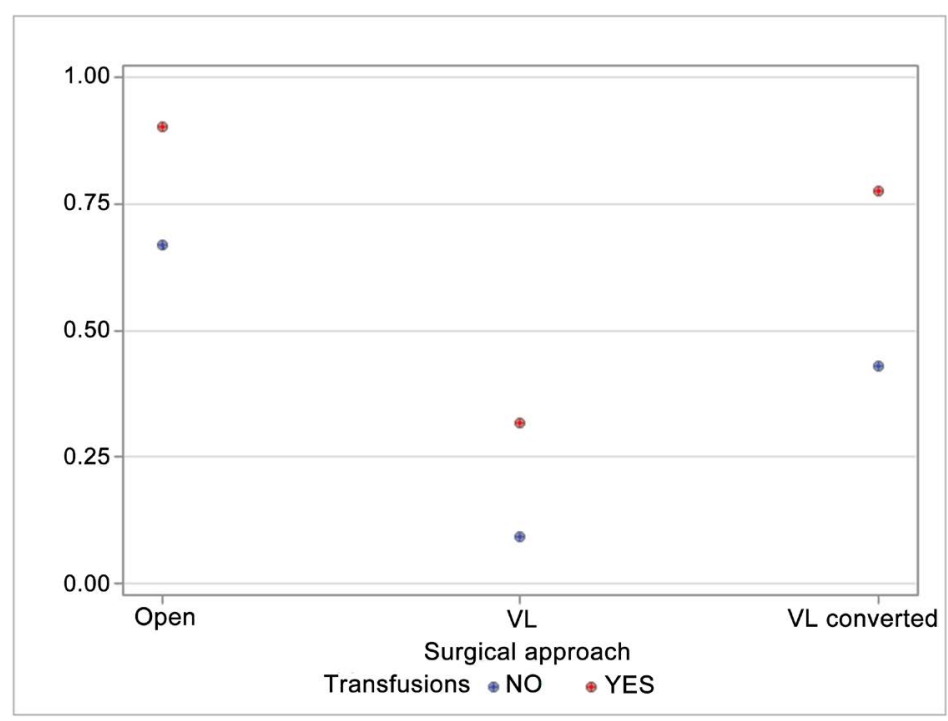

Figure 3. Complications probability considering transfusions and surgical approach. 


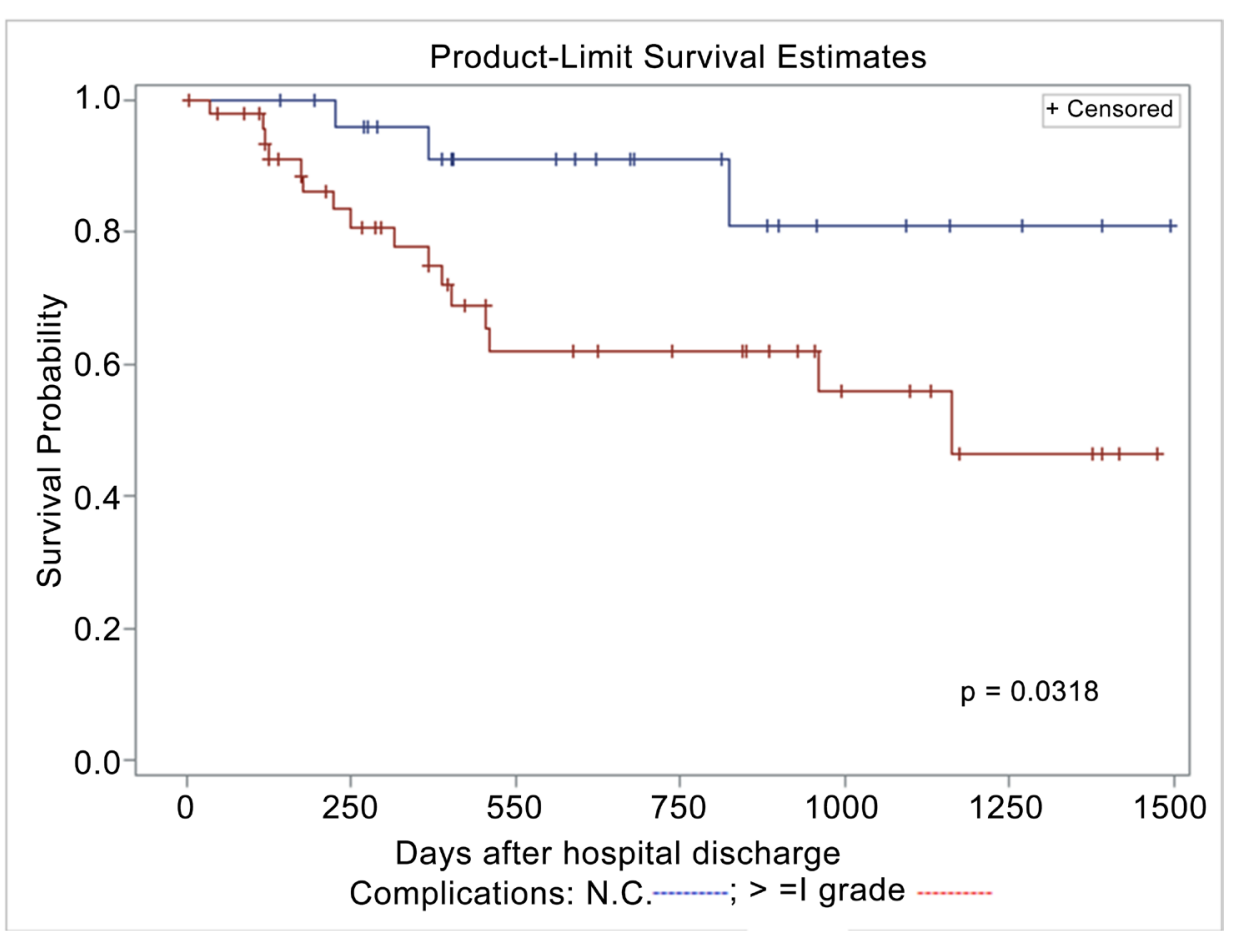

Figure 4. Complications and survival probability.

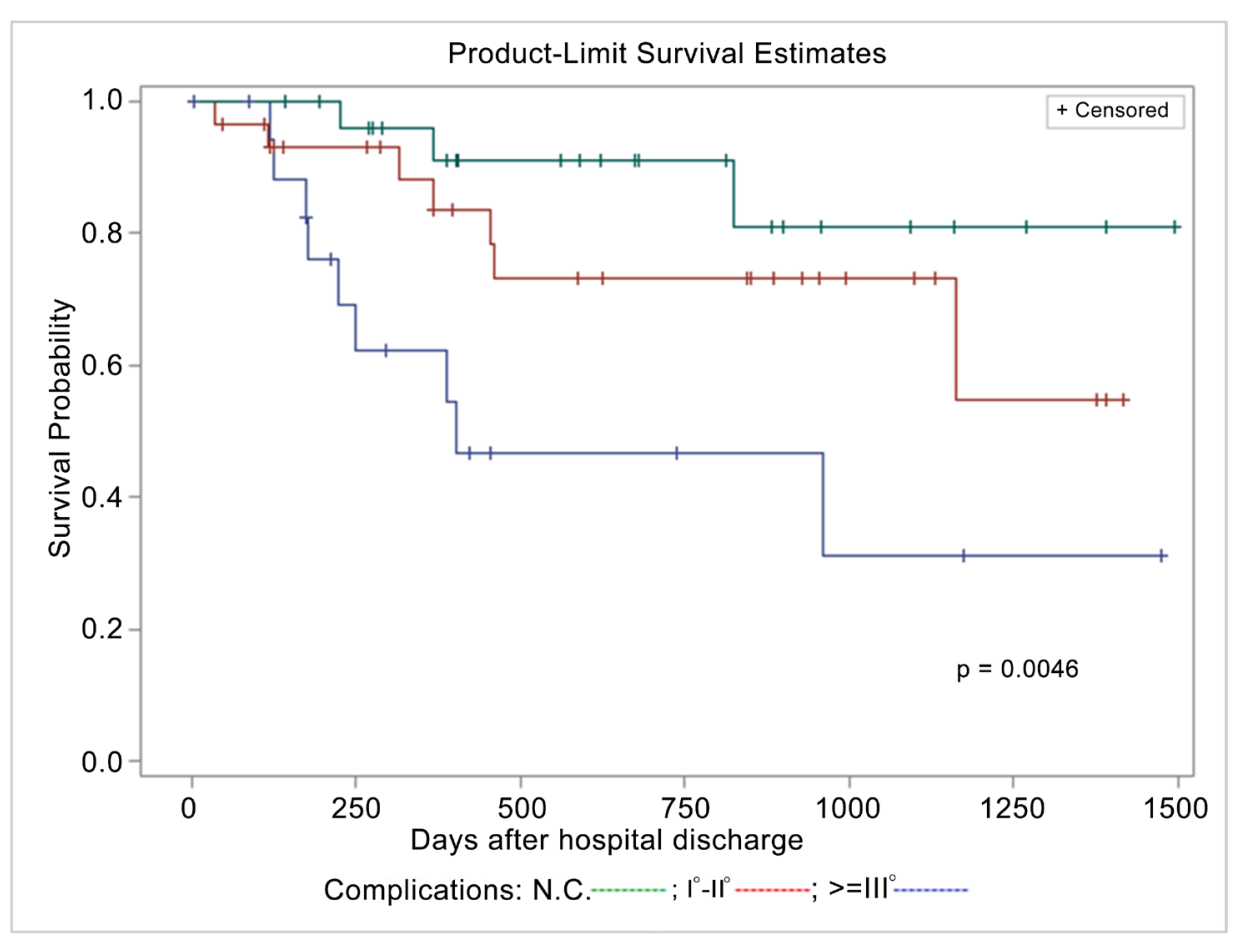

Figure 5. Complications and survival probability (II).

- Extent of resection: patients undergoing subtotal gastrectomy show a better prognosis than those undergoing total gastrectomy $(\mathrm{HR}=0.308 ; 95 \% \mathrm{CI}=0.098-0.966, \mathrm{p}=0.0434)$;

- Lymph node ratio: patients with $\mathrm{NR} \geq 0.2$ show a survival probability lower than those with $\mathrm{NR}=0$ (HR $=$ 14.380; $95 \% \mathrm{CI}=1.716-120.534, \mathrm{p}=0.0140$ ), whereas there is no difference between NR $=0$ and NR between 0 and $0.2(\mathrm{HR}=2.179 ; 95 \% \mathrm{CI}=0.201-23.607, \mathrm{p}=0.5218)$. 


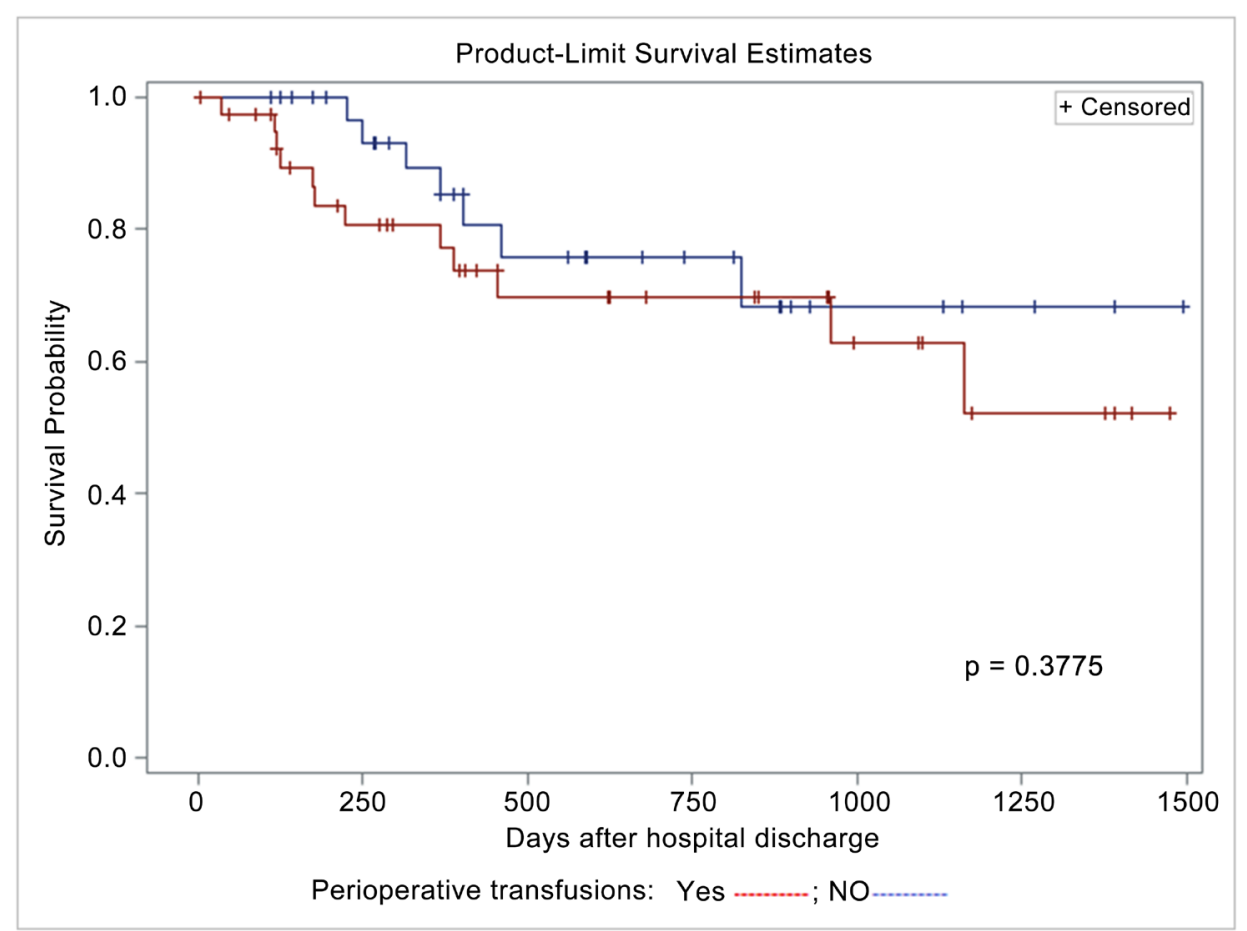

Figure 6. Perioperative transfusions and survival probability.

Table 6. Multivariate logistic regression model: risk factors and survival probability.

\begin{tabular}{|c|c|c|c|c|c|c|c|}
\hline \multicolumn{8}{|c|}{ Analysis of maximum likelihood estimates } \\
\hline \multicolumn{2}{|c|}{ Parameter } & $\begin{array}{c}\text { Parameter } \\
\text { estimate }\end{array}$ & $\begin{array}{c}\text { Standard } \\
\text { error }\end{array}$ & $\chi^{2}$ & $\mathbf{p}$ & $\begin{array}{c}\text { Hazard } \\
\text { ratio }\end{array}$ & $95 \%$ CI \\
\hline Complications & & 1.99954 & 0.76711 & 6.7944 & 0.0091 & 7.386 & $1.642-33.219$ \\
\hline Trasfusions & No & 1.01648 & 0.63223 & 2.5849 & 0.1079 & 2.763 & $0.8-9.54$ \\
\hline \multirow{2}{*}{ BMI } & Normal weight & 0.9845 & 0.59492 & 2.7386 & 0.098 & 2.676 & $0.834-8.588$ \\
\hline & Underweight & 2.12851 & 1.04308 & 4.164 & 0.0413 & 8.402 & $1.088-64.904$ \\
\hline \multirow{2}{*}{ Extent of resection } & Extended & -0.3498 & 0.60408 & 0.3353 & 0.5625 & 0.705 & $0.216-2.304$ \\
\hline & Subtotal & -1.17814 & 0.5833 & 4.0796 & 0.0434 & 0.308 & $0.098-0.966$ \\
\hline \multirow{2}{*}{ Lymph node ratio } & $>0,<0.2$ & 0.77875 & 1.21566 & 0.4104 & 0.5218 & 2.179 & $0.201-23.607$ \\
\hline & $\geq 0.2$ & 2.66581 & 1.08474 & 6.0395 & 0.014 & 14.38 & $1.716-120.534$ \\
\hline
\end{tabular}

\section{Discussion}

Our patients are representative of a western gastric cancer series whereas most studies on this item evaluate eastern people. Western patients suffer from greater heart, lung and metabolic comorbidities and have a higher BMI than eastern people [11]; moreover, gastric cancer is diagnosed at elder ages and in more advanced stages because of the lack of screening programs. Another difference concerns the histological features: gastric cancer in western countries is usually proximal and diffused according to Lauren classification and it has a more aggressive behaviour than the intestinal and distal one [12].

If we compare our findings with the results of the Clavien-Dindo study which included 6336 patients, the lower percentage of complications in this latter study is evident. However, some of the differences may be due to the inclusion in their group of patients who underwent minor surgical procedures [3]. 
Quing-Guo Li et al. [13] include only patients operated upon for gastric cancer and report $12.5 \%$ of patients with $\geq$ Grade I complications, which is exceedingly lower when compared with our finding of $65.3 \%$ of complications. However, the two groups seem hardly comparable, since in Quing-Guo Li's study the surgical technique isn't described and their series was made up of and patients with a lower ASA score and lower median age who were operated at an earlier stage.

Results similar to ours were obtained in Ju-Hee Lee et al. study [4], with an overall complication rate of 65.4\%, (25.3\% in patients undergoing laparoscopy and 40.1 in patients undergoing laparotomy). This higher complication rate is closely related to the precise application of the definition of complication as "any deviation from normal postoperative course": for example, asymptomatic fever or transient anomalies in laboratory tests are classified as Grade I and II complications, in spite of their conservative treatment. This type of complications represented the most part of the complications which were observed in both the Ju-Hee Lee's and our studies.

In our study, age is not a significant risk factor for complications, conversely other studies [2] [14] consider it a risk factor and the authors discourage this kind of surgery in older people.

The relationship between obesity and complications is still controversial: most studies report an increasing risk in obese patients, because of technical complexity due to poorer surgical exposure, blood oozing from soft tissue, dissection planes hindered by adipose tissue, difficulty with anastomoses, and so forth [15]. On the contrary, our study, consistently with other ones [16], has shown that BMI doesn't represent a risk factor for complications. These different results may be due to the fact that BMI doesn't distinguish between muscle and fat accumulation or between central and general obesity. Recently, a new anthropometric measure, "A Body Shape Index" (ABSI), has been proposed and when compared with BMI, it seems to better correlate with complications [17] [18].

Moreover, in our clinical records, obese patients were only 5 , all of whom belonged to class I obesity (BMI $\geq$ 30 and $<35$ ). This is the reason why no technical difficulties were due to the excess of adipose tissue in our series. On the contrary, all our patients with BMI $<18.5$ (underweight) developed postoperative complications. In our records they are represented by only 4 patients (5.4\%). However, similar results were reported by other studies in larger series [2].

As previously reported, overweight/obese patients may even have a better prognosis [19] [20]. These might be explained on the basis of the loss of weight, which occurs after gastric surgery [21] and which could restore the ideal weight in this category of patients.

Previous studies focused the attention between intraoperative bleeding loss (IBL) and complications [22] [23]. Unfortunately, IBL was not measured in our series. Therefore, only the transfusion datum could be utilized in the present series and a direct correlation between transfusion and post-operative complications was observed. On the contrary, the inverse correlation between transfusions and long-term survival which has been previously shown was not confirmed. However, most studies [24]-[26] have shown that perioperative surgical stress cause immunosuppression, which could be exacerbated by concomitant transfusions. This condition could promote tumor relapse and metastatic process and could be explained by the infusion of an incompatible MHC antigen.

The surgical technique seems to have a statistically significant effect: patients undergoing open surgery have a greater risk to develop complications than those undergoing laparoscopy. This finding agrees with other studies [4] [27] [28]. Ju-Hee Lee et al. [4] have reported that complications $\geq$ Grade I are present in $25.3 \%$ of patients undergoing laparoscopy and $40.1 \%$ undergoing laparotomy. Our results are similar: $27.3 \%$ and $77.1 \%$ of complications in patients undergoing laparoscopy and laparotomy, respectively $(\mathrm{p}=0.005)$. We also, as previously done [4], have separately considered "life-threatening" complications ( $\geq$ Grade IIIa). The results were as follows: patients operated with an open access had $20 \%$ of life threatening complications, (Ju-Hee Lee et al. [4] 5.4\%) whereas the laparoscopic group only 1.33\% (Ju-Hee Lee et al. [4] 2.1\%) (Table 7). Both series stand for the evidence that complications are not uncommon after open surgery. Li H.T. et al. [27] underline, despite a significantly longer operation time, the advantages which derive from laparoscopy: less intraoperative blood loss, shorter hospitalization time, shorter time to mobilization, shorter time to bowel opening and shorter time to normal dietary intake. These advantages could be explained by the reduction of the so-called "surgical stress" in laparoscopic surgery. How could it be measured? Toru Aoyama et al. [29] have compared surgical stress of laparotomic and laparoscopic procedures through the evaluation of the white blood cell count and the IL-6 level. They didn't find any differences between the two surgical approaches. Other authors [30]-[32] obtained the same results, although different methods for the evaluation were employed. 
Table 7. Technique vs complications in 3 levels.

\begin{tabular}{cccc}
\hline \multirow{2}{*}{ Technique } & \multicolumn{2}{c}{ Complications in 3 levels } & N.C \\
\cline { 2 - 4 } Open & 15 & $<$ III $^{\circ}$ & 11 \\
& 20.00 & 29.33 & 14.67 \\
& 31.25 & 45.83 & 22.92 \\
VL & 78.95 & 73.33 & 42.31 \\
& 1 & 2 & 8 \\
& 1.33 & 2.67 & 10.67 \\
VL converted & 9.09 & 18.18 & 72.73 \\
& 5.26 & 6.67 & 30.77 \\
& 3 & 6 & 7 \\
& 4.00 & 8.00 & 9.33 \\
\hline
\end{tabular}

As far as long-term results are concerned, no deaths were observed in the laparoscopic group, although differences in overall survival between the laparoscopic and laparotomic group were not attained.

Recently, robot-assisted gastrectomy has been introduced for gastric cancer treatment and its advantages/ disadvantages in comparison with the other techniques are under investigation. K.M. Kim et al. [33] underline that open surgery and minimally invasive approach achieve similar complication and mortality rates, but complications like anastomotic leaks are more common after the latter technique. According to M.H. Hyun metaanalysis, short term oncological outcomes are similar with all the three different operative approaches, minimally invasive surgery provides substantial advantages and more specifically laparoscopy is less time-consuming and expensive than robotic [34]. Koichi Suda et al. [35], adopting Clavien-Dindo classification, have compared laparoscopic and robotic approaches and pointed out that postoperative complications could be reduced by robotics. However, robotic approach to gastric cancer needs further experience before possible advantages may be fully understood.

In our study the duration of hospitalization proceeds at the same pace of the incidence of postoperative complications, but it cannot be considered as a risk factor for complications since it can be evaluated only a posteriori. However, it must be questioned whether complications influence the hospital stay or patients who have longer hospital stay have more probability to develop complications.

In this respect, possible benefits due to fast track surgery, must be underlined. In our study, stage of the disease and nodal status (i.e. NR) did not appear to be correlated with the incidence of complications. However, they are obviously related to the survival rate: NR was shown as an independent prognostic factor.

Our finding of a relationship between postoperative complications and reduction of survival probability is in agreement with previous papers [1] [5] [13]. Some hypotheses in order to explain these data may be put forward: postoperative complications may induce an extended period of immunosuppression due to generalized inflammation. This may lead to residual tumor cell increased survival and proliferation [1]. For several other malignancies perioperative blood transfusions correlated with negative immunomodulatory effects and earlier cancer recurrence [36]. Moreover it has been shown that infection and sepsis potentiate proinflammatory cytokine cascades. The immune modulators which are implied (TNF- $\alpha$, IL-1, IL-6, IL-8) could affect the function and regulation of natural killer cells [37]. Therefore, hypothetically, micrometastases may rapidly progress during brief and/or prolonged periods of relative immunosuppression due to postoperative complications. Moreover, both sepsis and blood transfusion may stimulate vascular endothelial growth factor (VEGF) release which is one of the most potent stimulators of metastatic growth. In this way transfusions and sepsis may stimulate cancer recurrence [38] [39].

The incidence of postoperative complications varies according to the different classifications. Recently, the 
Clavien-Dindo system, which is characterized by objectivity and reproducibility, has been proposed for and applied to most surgical specialties. For this reason it makes possible comparisons between different series. The present results, as previously reported in an interim analysis [40], could be considered similar to those in the literature in spite they mostly concern eastern series.

Significant risk factor for postoperative complications are represented by surgical approach and pre/intraoperative transfusions. Laparoscopic approach appears to be capable of reducing post-operative complications and of increasing overall survival. Moreover, patients who didn't receive transfusions in the perioperative period showed lower incidence of complications.

The effect of complications on long term survival seems also worth of notice. According to several studies the inflammatory response determined by complications, as well as by transfusions, cause immunosuppression, which, in turn, could promote neoplastic cell proliferation and metastatic potentiality.

\section{Conclusion}

In view of these findings, two strategies may be consequently adopted. First of all it seems useful to promote laparoscopic approach (that, in turn, reduces intraoperative blood loss and postoperative complications) and anyway to discourage perioperative transfusions in oncologic patients. In this respect, when needed, alternative methods must be used in order to improve hemoglobin levels in the preoperative period. Secondly, because of the relevant impact of postoperative complications on prognosis, an adequate perioperative care is mandatory in order to prevent complications due to possible comorbidities.

\section{References}

[1] Kubota, T., Hiki, N., Sano, T., Nomura, S., et al. (2014) Prognostic Significance of Complications after Curative Surgery for Gastric Cancer. Annals of Surgical Oncology, 21, 891-898. http://dx.doi.org/10.1245/s10434-013-3384-9

[2] Lee, K.G., Lee, H.J., Yang, J.Y., et al. (2014) Risk Factors Associated with Complication Following Gastrectomy for Gastric Cancer: Retrospective Analysis of Prospectively Collected Data Based on the Clavien-Dindo System. Journal of Gastrointestinal Surgery, 18, 1269-1277. http://dx.doi.org/10.1007/s11605-014-2525-1

[3] Dindo, D., Demartines, N. and Clavien, P.A. (2004) Classification of Surgical Complications: A New Proposal with Evaluation in a Cohort of 6336 Patients and Results of a Survey. Annals of Surgery, 240, 205-213. http://dx.doi.org/10.1097/01.sla.0000133083.54934.ae

[4] Lee, J.H., Park, D.J., Kim, H.H., Lee, H.J. and Yang, H.K. (2012) Comparison of Complications after LaparoscopyAssisted Distal Gastrectomy and Open Distal Gastrectomy for Gastric Cancer Using the Clavien-Dindo Classification. Surgical Endoscopy, 26, 1287-1295. http://dx.doi.org/10.1007/s00464-011-2027-0

[5] Jiang, N., Deng, J.Y., Ding, X.W., Zhang, L., Liu, H.G., Liang, Y.X. and Liang, H. (2014) Effect of Complication Grade on Survival Following Curative Gastrectomy for Carcinoma. World Journal of Gastroenterology, 20, 82448252. http://dx.doi.org/10.3748/wjg.v20.i25.8244

[6] Novara, G., Ficarra, V., D’Elia, C., Secco, S., Cavalleri, S. and Artibani, W. (2010) Prospective Evaluation with Standardised Criteria for Postoperative Complications after Robotic-Assisted Laparoscopic Radical Prostatectomy. European Urology, 57, 363-370. http://dx.doi.org/10.1016/j.eururo.2009.11.032

[7] Wechter, M.E., Mohd, J., Magrina, J.F., Cornella, J.L., Magtibay, P.M., Wilson, J.R. and Kho, R.M. (2014) Complications in Robotic-Assisted Gynecologic Surgery According to Case Type. A Six-Year Retrospective Cohort Study Using Clavien-Dindo Classification. Journal of Minimally Invasive Gynecology, 21, 844-850. http://dx.doi.org/10.1016/j.jmig.2014.03.016

[8] Sink, E.L., Leunig, M., Zaltz, I., Gilbert, J.C. and Clohisy, J. (2012) Reliability of a Complication Classification System for Orthopedic Surgery. Clinical Orthopaedics and Related Research, 470, 2220-2226. http://dx.doi.org/10.1007/s11999-012-2343-2

[9] Orsenigo, E., Bissolati, M., Socci, C., Chiari, D., Muffatti, F., Nifosi, J. and Staudacher, C. (2014) Duodenal Stump Fistula after Gastric Surgery for Malignancies: A Retrospective Analysis of Risk Factors in a Single Centre Experience. Gastric Cancer, 17, 733-744. http://dx.doi.org/10.1007/s10120-013-0327-x

[10] de Manzoni, G., Roviello, F. and Squini, W. (2012) Surgery in the Multimodal Management of Gastric Cancer, Foreword by Keiichi Maruyama GIRCG. Springer-Verlag, Italia.

[11] http://www.iss.it/lgac/docu/cont.php?id=278\&lang=1\&tipo=\%2032

[12] Bickendach, K. and Strong, V.E. (2012) Comparisons of Gastric Cancer Treatments: East vs. West. Journal of Gastric Cancer, 12, 55-62. http://dx.doi.org/10.5230/jgc.2012.12.2.55 
[13] Li, Q.G., Li, P., Tang, D., Chen, J. and Wang, D.R. (2013) Impact of Postoperative Complications on Long-Term Survival after Radical Resection for Gastric Cancer. World Journal of Gastroenterology, 19, 4060-4065. http://dx.doi.org/10.3748/wjg.v19.i25.4060

[14] Hayashi, T., Yoshikawa, T., Aoyama, T., Ogata, T., Cho, H. and Tsuburaya, A. (2012) Severity of Complications after Gastrectomy in Elderly Patients with Gastric Cancer. World Journal of Surgery, 36, 2139-2145. http://dx.doi.org/10.1007/s00268-012-1653-6

[15] Pata, G., Solaini, L., Roncali, S., Pasini, M. and Ragni, F. (2013) Impact of Obesity on Early Surgical and Oncologic Outcomes after Total Gastrectomy with “Over-D1” Lymphadenectomy for Gastric Cancer. World Journal of Surgery, 37, 1072-1081. http://dx.doi.org/10.1007/s00268-013-1942-8

[16] Fraczek, M., Jeziorski, A., Krawczyk, M., Starzynska, T. and Wallner, G. (2010) Implications of Overweight in Gastric Cancer: A Multicenter Study in a Western Patient Population. European Journal of Surgical Oncology, 36, 969-976. http://dx.doi.org/10.1016/i.ejso.2010.07.007

[17] Eom, B.W., Joo, J., Yoon, H.M., Ryu, K.W., Kim, Y.W. and Lee, J.H. (2014) A Body Shape Index Has a Good Correlation with Postoperative Complications in Gastric Cancer Surgery. Annals of Surgical Oncology, 21, 1115-1122. http://dx.doi.org/10.1245/s10434-013-3409-4

[18] Krakauer, N.Y. and Krakauer, J.C. (2012) A New Body Shape Index Predicts Mortality Hazard Independently of Body Mass Index. PLOS ONE, 7, e39504. http://dx.doi.org/10.1371/journal.pone.0039504

[19] Wu, M.H., Lin, M.T. and Chen, W.J. (2008) Effect of Perioperative Parenteral Nutritional Support for Gastric Cancer Patients Undergoing Gastrectomy. Hepatogastroenterology, 55, 799-802.

[20] Kong, F., Li, H., Fan, Y., Zhang, X.W., Cao, S., Yu, J.P., et al. (2013) Overweight Patients Achieve Ideal Body Weight Following Curative Gastrectomy Resulting in Better Long-Term Prognosis. Obesity Surgery, 23, 650-656. http://dx.doi.org/10.1007/s11695-012-0847-1

[21] Kiyama, T., Mizutani, T., Okuda, T., Fujita, I., Tokunaga, A., Tajiri, T., Barbul, A., et al. (2005) Postoperative Changes in Body Composition after Gastrectomy. Journal of Gastrointestinal Surgery, 9, 313-319. http://dx.doi.org/10.1016/j.gassur.2004.11.008

[22] Sah, B.K., Zhu, Z.G., Chen, M.M., Xiang, M., Chen, J., Yan, M. and Lin, Y.Z. (2009) Effect of Surgical Work Volume on Postoperative Complication: Superiority of Specialized Center in Gastric Cancer Treatment. Langenbeck's Archives of Surgery, 394, 41-47. http://dx.doi.org/10.1007/s00423-008-0358-7

[23] Liang, Y.X., Guo, H.H., Deng, J.Y., Wang, B.G., Ding, X.W., Wang, X.N., et al. (2013) Impact of Intraoperative Blood Loss on Survival after Curative Resection for Gastric Cancer. World Journal of Gastroenterology, 19, 55425550. http://dx.doi.org/10.3748/wjg.v19.i33.5542

[24] Sutton, J.M., Kooby, D.A., Wilson, G.C., Squires III, M.H., Hanseman, D.J., Maithel, S.K., et al. (2014) Perioperative Blood Transfusion Is Associated with Decreased Survival in Patients Undergoing Pancreaticoduodenectomy for Pancreatic Adenocarcinoma: A Multi-Institutional Study. Journal of Gastrointestinal Surgery, 18, 1575-1587.

[25] Waters, J.H., Yazer, M., Chen, Y.F. and Kloke, J. (2012) Blood Salvage and Cancer Surgery: A Meta-Analysis of Available Studies. Transfusion, 52, 2167-2173. http://dx.doi.org/10.1111/j.1537-2995.2011.03555.x

[26] Adamina, M., Gié, O., Demartines, N. and Ris, F. (2013) Contemporary Perioperative Care Strategies. British Journal of Surgery, 100, 38-54. http://dx.doi.org/10.1002/bjs.8990

[27] Li, H.T., Han, X.P., Su, L., Zhu, W.-K., Xu, W., Li, K., et al. (2014) Short-Term Efficacy of Laparoscopy-Assisted vs. Open Radical Gastrectomy in Gastric Cancer World. Journal of Gastrointestinal Surgery, 6, 59-64.

[28] Cheng, Q., Pang, T.C.Y., Hollands, M.J., Richardson, A.J., Pleass, H., Johnston, E.S. and Lam, V.W.T. (2014) Systematic Review and Meta-Analysis of Laparoscopic versus Open Distal Gastrectomy. Journal of Gastrointestinal Surgery, 18, 1087-1099. http://dx.doi.org/10.1007/s11605-014-2519-z

[29] Aoyama, T., Yoshikawa, T., Hayashi, T., Hasegawa, S., Tsuchida, K., Yamada, T., et al. (2014) Randomized Comparison of Surgical Stress and the Nutritional Status between Laparoscopy-Assisted and Open Distal Gastrectomy for Gastric Cancer. Annals of Surgical Oncology, 21, 1983-1990. http://dx.doi.org/10.1245/s10434-014-3509-9

[30] Huscher, C.G., Mingoli, A., Sgarzini, G., Sansonetti, A., Di Paola, M., Recher, A. and Ponzano, C. (2005) Laparoscopic versus Open Subtotal Gastrectomy for Distal Gastric Cancer: Five-Year Results of a Randomized Prospective Trial. Annals of Surgery, 241, 232-237. http://dx.doi.org/10.1097/01.sla.0000151892.35922.f2

[31] Adachi, Y., Shiraishi, N., Shiromizu, A., Bandoh, T., Aramaki, M. and Kitano, S. (2000) Laparoscopy-Assisted Billroth I Gastrectomy Compared with Conventional Open Gastrectomy. Annals of Surgery, 135, 806-810. http://dx.doi.org/10.1001/archsurg.135.7.806

[32] Kim, H.H., Hyung, W.J., Cho, G.S., Kim, M.C., Han, S.-U., Kim, W., et al. (2010) Morbidity and Mortality of Laparoscopic Gastrectomy versus Open Gastrectomy for Gastric Cancer: An Interim Report-A Phase III Multicenter, Prospective, Randomized Trial (KLASS Trial). Annals of Surgery, 251, 417-420. 
http://dx.doi.org/10.1097/SLA.0b013e3181cc8f6b

[33] Kim, K.M., An, J.Y., Kim, H.I., Cheong, J.H., Hyung, W.J. and Noh, S.H. (2012) Major Early Complications Following Open, Laparoscopic and Gastrectomy. British Journal of Surgery, 99, 1681-1687. http://dx.doi.org/10.1002/bjs.8924

[34] Hyun, M.H., Lee, C.H., Kim, H.J., Ton, Y. and Park, S.S. (2013) Systematic Review and Meta-Analysis of Robotic Surgery Compared with Conventional Laparoscopic and Open Resections for Gastric Carcinoma. British Journal of Surgery, 100, 1566-1578.

[35] Suda, K., Man-I, M., Ishida, Y., Kawamura, Y., Satoh, S. and Uyama, I. (2014) Potential Advantages of Robotic Radical Gastrectomy for Gastric Adenocarcinoma in Comparison with Conventional Laparoscopic Approach: A Single Institutional Retrospective Comparative Cohort Study. Surgical Endoscopy.

[36] Katz, S.C., Shia, J., Liau, K.H., Gonen, M., Ruo, L., Jarnagin, W.R., Fong, Y., et al. (2009) Operative Blood Loss Independently Predicts Recurrence and Survival after Resection of Hepatocellular Carcinoma. Annals of Surgery, 249, 617-623. http://dx.doi.org/10.1097/SLA.0b013e31819ed22f

[37] Balkwill, F. and Mantovani, A. (2001) Inflammation and Cancer: Back to Virchow? The Lancet, 357, 539-545. http://dx.doi.org/10.1016/S0140-6736(00)04046-0

[38] Mynster, T., Christensen, I.J., Moesgaard, F. and Nielsen, H.J. (2000) Effect of the Combination of Blood Transfusion and Postoperative Infectious Complications on Prognosis after Surgery for Colorectal Cancer. British Journal of Surgery, 87, 1553-1562. http://dx.doi.org/10.1046/j.1365-2168.2000.01570.x

[39] Nash, G.F., Chopada, A., Patel, H. and Kakkar, A.K. (2002) Stored Blood Products Stimulate Cancer Growth. British Journal of Surgery, 89, 19. http://dx.doi.org/10.1046/j.1365-2168.89.s.1.9_10.x

[40] GIRCG (2013) Tailored and Multidisciplinary Gastric Cancer Treatment. Proceedings of the 10th International Gastric Cancer Congress, Verona, 19-22 June 2013. 
Scientific Research Publishing (SCIRP) is one of the largest Open Access journal publishers. It is currently publishing more than 200 open access, online, peer-reviewed journals covering a wide range of academic disciplines. SCIRP serves the worldwide academic communities and contributes to the progress and application of science with its publication.

Other selected journals from SCIRP are listed as below. Submit your manuscript to us via either submit@scirp.org or Online Submission Portal.
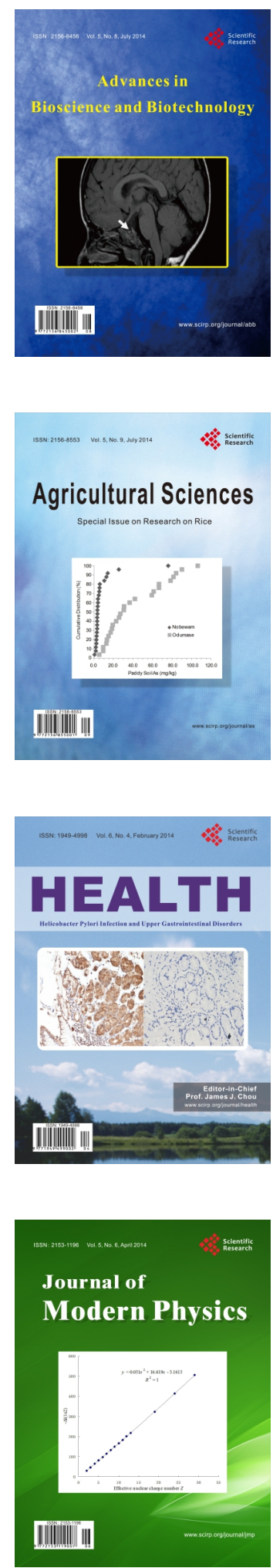
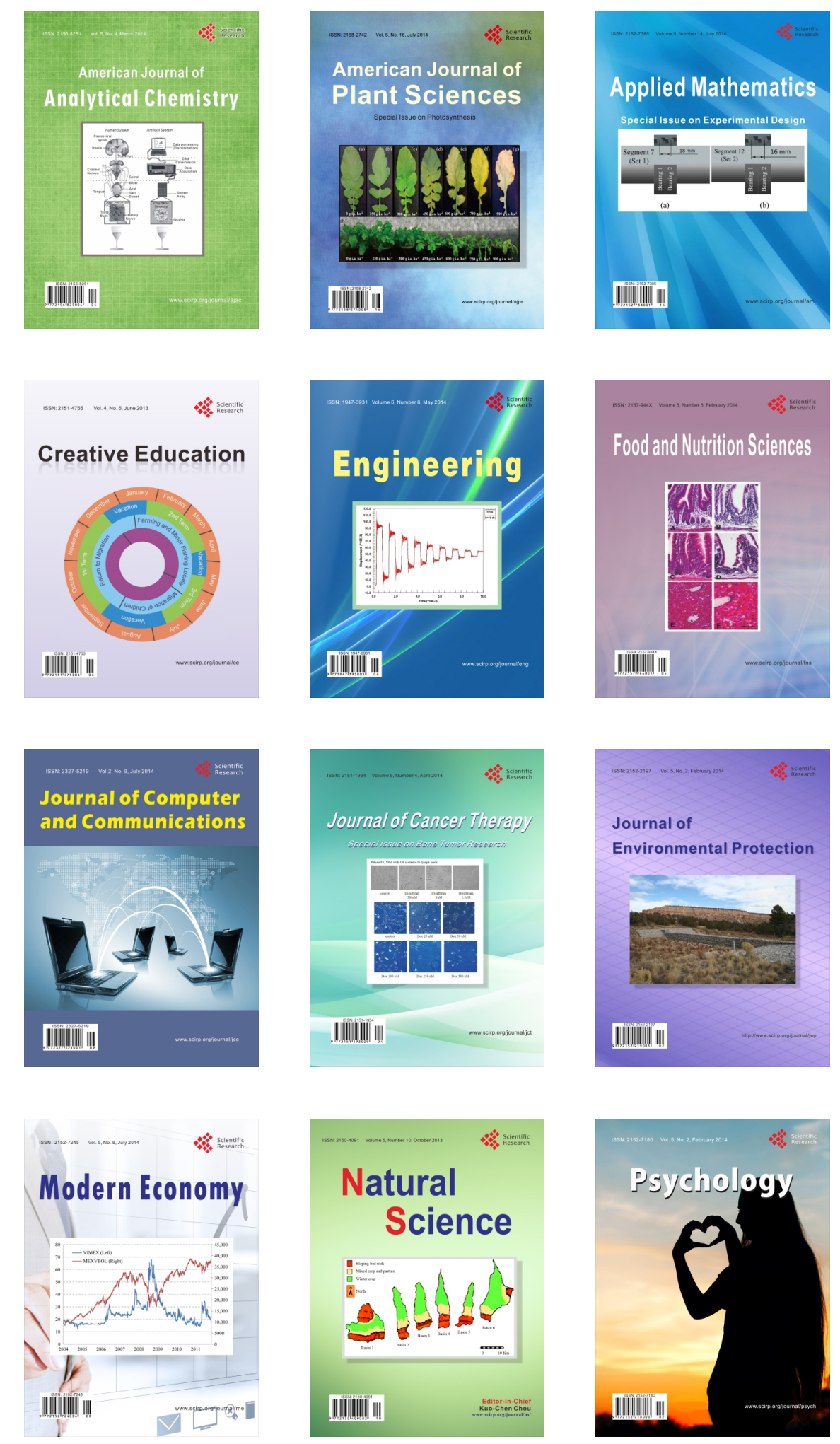